\title{
Mercury and Beyond: Diode-Pumped Solid-State Lasers for Inertial Fusion Energy
}

C. Bibeau, A. Bayramian, R.J. Beach, J.C. Chanteloup, C.A. Ebbers, M.A. Emanuel, C.D. Orth, S.A. Payne, J.E. Rothenberg, H.T. Powell, K.I. Schaffers, J.A. Skidmore, S.B. Sutton, L.E. Zapata

This article was submitted to SPIE Advanced High Power Lasers and Applications, Osaka, Japan, November 1-5, 1999

U.S. Department of Energy

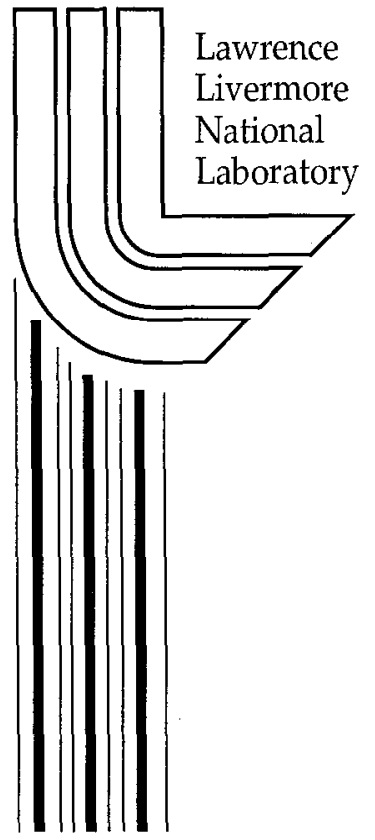

December 1, 1999 


\section{DISCLAIMER}

This document was prepared as an account of work sponsored by an agency of the United States Government. Neither the United States Government nor the University of California nor any of their employees, makes any warranty, express or implied, or assumes any legal liability or responsibility for the accuracy, completeness, or usefulness of any information, apparatus, product, or process disclosed, or represents that its use would not infringe privately owned rights. Reference herein to any specific commercial product, process, or service by trade name, trademark, manufacturer, or otherwise, does not necessarily constitute or imply its endorsement, recommendation, or favoring by the United States Government or the University of California. The views and opinions of authors expressed herein do not necessarily state or reflect those of the United States Government or the University of California, and shall not be used for advertising or product endorsement purposes.

This is a preprint of a paper intended for publication in a journal or proceedings. Since changes may be made before publication, this preprint is made available with the understanding that it will not be cited or reproduced without the permission of the author.

This report has been reproduced

directly from the best available copy.

Available to DOE and DOE contractors from the

Office of Scientific and Technical Information

P.O. Box 62, Oak Ridge, TN 37831

Prices available from (423) 576-8401

http://apollo.osti.gov/bridge/

Available to the public from the National Technical Information Service

U.S. Department of Commerce

5285 Port Royal Rd.,

Springfield, VA 22161

hllp://www.ntis.gov/

OR

Lawrence Livermore National Laboralory

Technical Information Department's Digital Library

http://www.llnl.gov/tid/Library.html 


\title{
Mercury and Beyond: Diode-Pumped Solid-State Lasers for Inertial Fusion Energy
}

\author{
C. Bibeau, A. Bayramian, R. J. Beach, J. C. Chanteloup, C. A. Ebbers, \\ M. A. Emanuel, C. D. Orth, S. A. Payne,J. E. Rothenberg, H. T. Powell, K. I. Schaffers, \\ J. A. Skidmore, S. B. Sutton, L. E. Zapata \\ Lawrence Livermore National Laboratory \\ 7000 east Ave. Livermore, CA 94550-9234 USA
}

\begin{abstract}
We have begun building the "Mercury" laser system as the first in a series of new generation diode-pumped solid-state lasers for inertial fusion research. Mercury will integrate three key technologies: diodes, crystals, and gas cooling, within a unique laser architecture that is scalable to kilojoule and megajoule energy levels for fusion energy applications. The primary near-term performance goals include $10 \%$ electrical efficiencies at $10 \mathrm{~Hz}$ and $100 \mathrm{~J}$ with a $2-10 \mathrm{~ns}$ pulse length at $1.047 \mu \mathrm{m}$ wavelength. When completed, Mercury will allow rep-rated target experiments with multiple chambers for high energy density physics research.
\end{abstract}

\section{Introduction}

The ultimate goal of ICF is to build a power plant based on laser fusion ${ }^{1}$. The top-level requirements for the IFE driver itself are:

- Efficiency, $>5 \%$

- Reliability, availability and maintainability, $>10^{9}$ shots

- Cost, $<\$ 1.5 \mathrm{~B}$

- Beam smoothness for direct drive, $<1 \%$ on-target for $<1 \mathrm{nsec}$

- Wavelength, $<0.4 \mu \mathrm{m}$

The efficiency of the IFE driver is important, since together with the target gain and costs, it determines the recycled power needed for the driver. The reliability and cost requirements follow from the need to produce commercially attractive electric power with a minimum 30-year plant lifetime. The beam smoothness and wavelength requirements derive from 25 years of experience in laser fusion, which have been reviewed in recent papers on direct drive ${ }^{2}$ and indirect drive. ${ }^{3}$

Gas-cooled, diode-pumped, Yb:crystal lasers are envisioned to be the next-generation ICF solid state laser system producing high energy per pulse at modest rep-rates. The diode-pumped solid state laser (DPSSL) approach builds on the last two decades of solid state laser development but also adds several imposing challenges -- repetition rate, reliability, and cost. Innovative solutions for building ICF lasers with high repetition rate and efficiency include:

- Trading the flashlamps for large, low-cost laser diode arrays

- Using Yb:crystals for greater energy storage and thermal conductivity than Nd:glass

- Employing near-sonic helium for cooling of the laser slabs

The Mercury Laser is the first step in integrating these new approaches, and in producing new capabilities for irradiating ICF targets. The primary performance goals for the Mercury Laser are to build a $100 \mathrm{~J}$ laser with $10 \%$ efficiency that operates at $10 \mathrm{~Hz}$-repetition rate. 


\section{Laser architecture}

The Mercury laser design (Fig. 1) is predicated upon employing three technological advances: efficient and reliable diodes operating at $900 \mathrm{~nm}$, Yb-doped crystals that offer longer storage lifetimes than the traditional Nd-doped materials, and active cooling with near-sonic helium gas flow across the crystalline laser slabs for rep-rated operation. The system layout incorporates an oscillator, pre-amplifier, and two power amplifiers. The gas-cooled power amplifiers are four-passed in an angular multiplexing scheme. An adaptive optic in the beamline will be used to correct for wavefront distortions incurred during amplification.

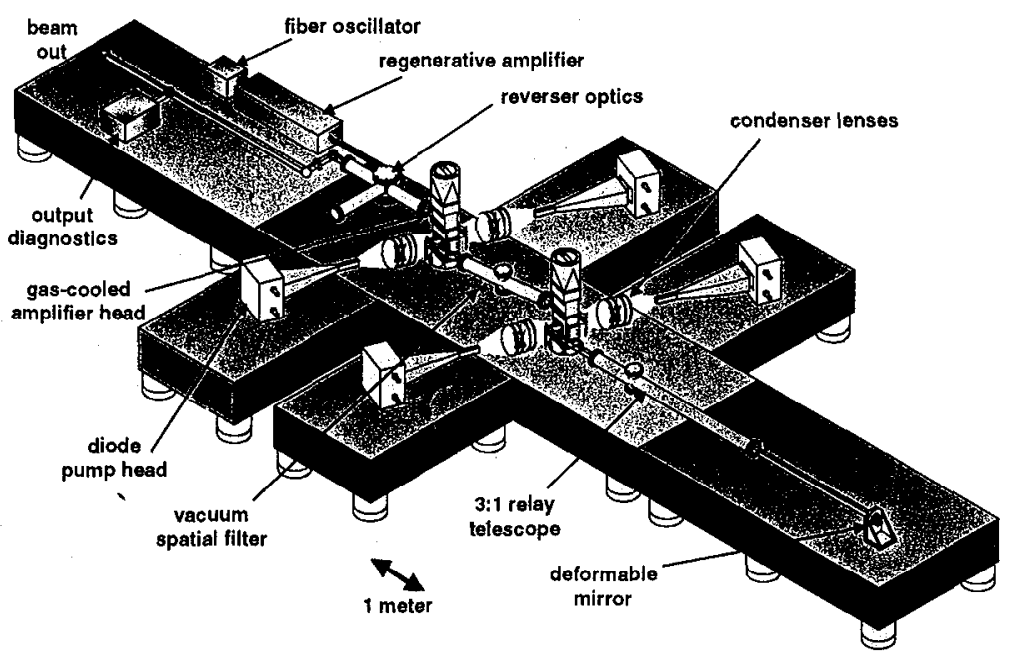

Fig. 1 Mercury laser schematic.

The amplifier head will be optically pumped from both sides. The dual pumping design allows for more uniform pumping and thermal loading on the crystals. The light from the diode array light is first concentrated with a hollow lens duct ${ }^{4}$ followed by a hollow element that homogenizes spatial profile of the pump beam. Both the duct and the homogenizer are coated on the inside with a protected silver coating. The light emerging from the output of the homogenizer is imaged onto the gain media with a set of four condenser lenses designed to minimize the spatial aberrations. The angled dichroic beam splitters allow the pump beam to pass through the optic and into the amplifier head while allowing the extraction beam to be reflected. We have assembled one out of four pump delivery arms as shown in Fig. 2 below.

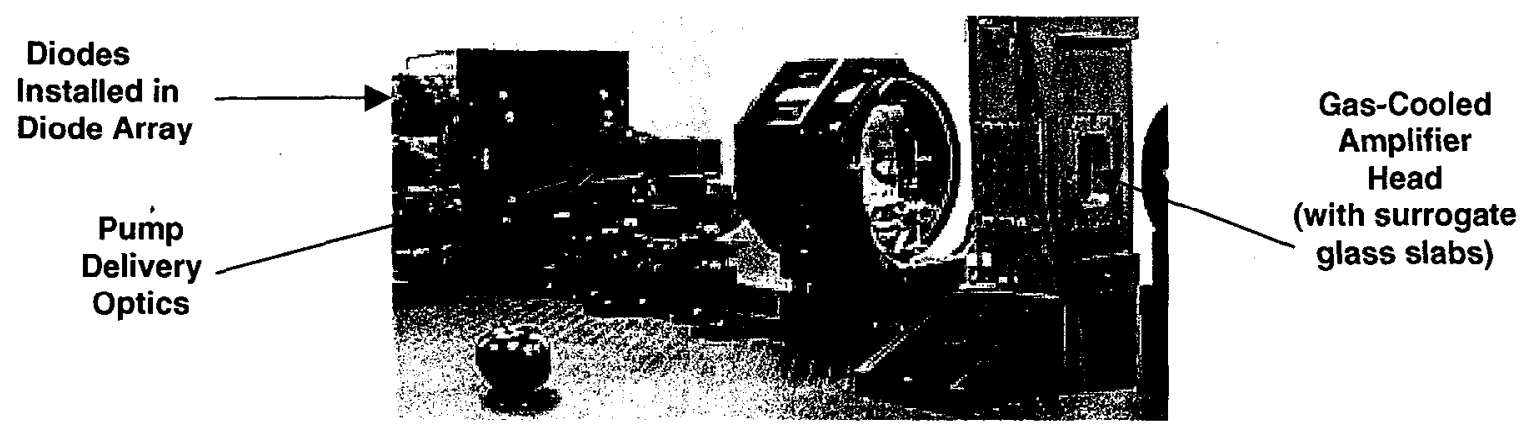

Fig. 2. Picture of one of four diode pump delivery arms.

In order to fully test the amplifier head and pump delivery system this year, surrogate gain media (Nd:glass) were placed in the vane elements within the amplifier head. This allows us 
to test the pump delivery efficiency, pump light uniformity within the laser slabs, gas flow dynamics, and thermal deposition profiles. Once the Yb:S-FAP crystals are ready, we can easily switch the surrogate slabs with the crystals. This approach will allow us to test the key elements in parallel with our efforts to develop adequately large crystals.

\section{Diodes}

A critical technology for realizing inertial fusion energy is in the cost and efficiency of laser diode arrays. Existing diode technical performance specifications do not currently meet the demanding requirements of IFE. In addition, the manufacturing costs will have to be reduced by approximately two orders of magnitude to make IFE economically viable. Together with an industrial partner, Coherent-Tutcore, we made significant progress on the development of aluminum-free $900 \mathrm{~nm}$ laser diode bars. We packaged, characterized and life-tested two 40-bar arrays of $900 \mathrm{~nm}$ laser bars using this diode material as shown in Fig. 3.

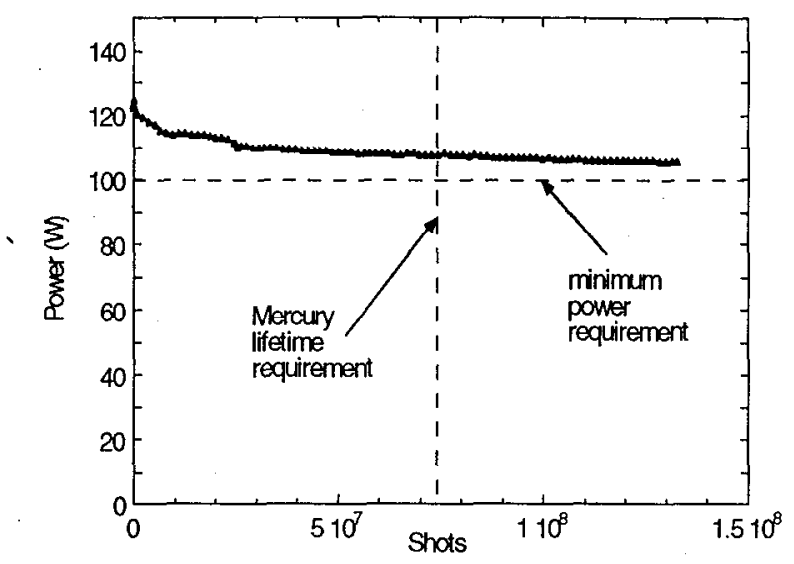

Fig. 3. Lifetest data for $900 \mathrm{~nm}$ diode material. The material exhibits $<20 \%$ degradation over $10^{8}$ shots under the Mercury conditions: $750 \mu \mathrm{s}, 10 \mathrm{~Hz}$ operation. The power per bar is noted on the plot.

\section{Amplifier head}

The Mercury laser amplifier head and gas cooled architecture has been designed in a modular and scalable fashion, with the laser slabs mounted in an aerodynamic vane element as
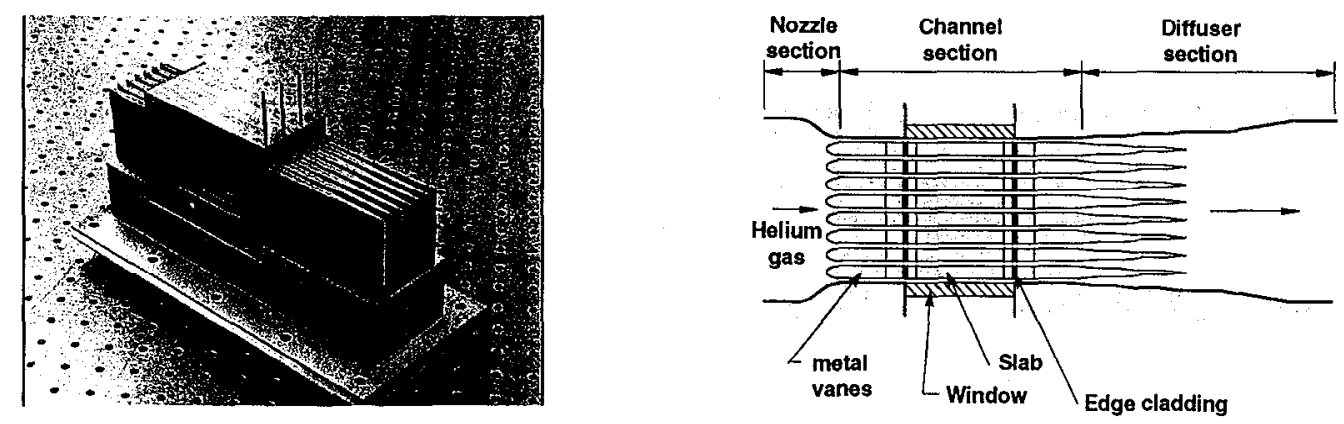

Fig. 4. (a) Actual vanes in assembly. (b) A schematic cross-section through the amplifier head, showing the cooling passages between vanes

depicted in Fig. 4a. The vane elements are then stacked in a manner that forms a cooling channel between pairs of vanes, as depicted in Fig. 4b. Gas flows over the faces of the laser slabs, in the 
cooling channel, to remove the waste heat generated during the lasing process. ${ }^{5,6}$ The assembled slab and vane cassette is then inserted into the amplifier head. The first laser head assembly was fabricated and installed in the Mercury laboratory, as shown in Fig. 2.

\section{Crystal growth}

Significant progress has been made in understanding the growth characteristics and defect chemistry of $\mathrm{Yb}: \mathrm{S}-\mathrm{FAP}\left[\mathrm{Yb}^{3+}: \mathrm{Sr}_{5}\left(\mathrm{PO}_{4}\right)_{3} \mathrm{~F}\right]$ crystals. The Mercury laser requires crystalline slabs of dimension $4 \times 6 \times 0.75 \mathrm{~cm}$. The growth of full size crystals has been a challenge due to a number of defects, including: cloudiness in as-grown boules, bubble core defects, grain boundaries, and cracking in larger diameter boules $>4.0 \mathrm{~cm}$. An effort is underway to understand each of these defects and determine a reproducible growth technique for producing high optical quality crystals. Results have produced boules with greatly reduced defects that have optical properties that nearly meet the Mercury specifications. The current plan is to produce high quality crystals of $4.5 \mathrm{~cm}$ diameter from which two half slabs can be cut and diffusion bonded together to make adequately large crystals for Mercury.

\section{Beyond Mercury}

A major objective of the present effort relates to establishing the readiness of the Mercury DPSSL driver to proceed to the next stage and beyond. The reliability, availability and maintainability of the laser components should be deemed to be acceptable for a future integrated research experiment or IRE (kJ-class laser coupled with average-power target chamber), and have a plausible means of attaining the driver requirements of inertial fusion energy (IFE) ${ }^{7}$. One possible vision of an IRE is based on a $4 \mathrm{~kJ}$ DPSSL composed of four 1-kJ beamlets. This DPSSL would test performance at gain-limited aperture size as well as multiaperture bundling technique needed to scale to very high energy. Most of the uses described above, including the neutron source, could be accomplished with the $4 \mathrm{~kJ}$ DPSSL of an IRE. A key feature of DPSSLs is that they are quite likely to achieve the efficiency required for direct drive target $(>5 \%)$, and that they may also reach the efficiency required for indirect drive targets (10-20\%). Morcover, they have the inherent capability of providing the high-energy picosecond pulses needed for the advanced fast ignition approach.

\section{Summary}

When completed Mercury will be the highest energy/pulse diode-pumped laser ever built by an order of magnitude that offers the dimension of high repetition rate $(\sim 10 \mathrm{~Hz})$. It will motivate the development of rep-rated targets and diagnostic capabilities. In addition, a major objective of the Mercury laser relates to establishing the readiness of the Mercury DPSSL driver to proceed to the next stage and beyond for fusion energy. ${ }^{1}$

\section{References:}

1 W. J. Hogan, ed., Energy from Inertial Fusion (International Atomic Energy Agency, Vienna, 1995).

2 S. E. Bodner, et al., Physics of Plasmas 5 1901-1917 (1998).

3 J. D. Lindl, Physics of Plasmas 2, 3933 (1995).

4 R. J. Beach, Appl. Opt., 35, 2005 (1996).

5 S. B. Sutton and G. F. Albrecht, J. Appl. Phys. 69, 1183 (1991).

${ }^{6}$ G. F. Albrecht, et al., Appl. Opt. 29, 3079 (1990).

7 C. D. Orth, S. A. Payne, and W. F. Krupke, Nuclear Fusion 36(1), 75 (1996).

This work was performed under the auspices of the U.S. Department of Energy by Lawrence Livermore National Laboratory under Contract No. W-7405-Eng-48. 